\title{
Using Video Recordings to Facilitate Student Development of Oral Presentation Skills
}

\author{
Kulawadee Yamkate \\ King Mongkut's University of Technology Thonburi, Thailand \\ Charatdao Intratat \\ King Mongkut's University of Technology Thonburi, Thailand
}

\begin{abstract}
Lack of confidence and ineffective preparation are believed to be major obstacles experienced by Thai students required to give oral presentations in English. Self-assessment is one possible solution to help students with this problem. This study was conducted with a group of Thai university students to find out (a) whether and (b) how video recordings facilitate the students' evaluation of their oral presentation skills and use of their evaluations to improve their performance. The research instruments were video recordings of the students' two presentations and questionnaires that asked the students to reflect on their strengths and weaknesses in both presentations. The data shows that the students had positive attitudes towards video recording their presentations, especially since this helped them to notice and identify their weaknesses in non-verbal language use. Overall, the process studied was found to facilitate the students' self-evaluation skills, resulting in the improvement of their presentation skills.
\end{abstract}

Learner-centeredness has been a concern of educators since the late 1960s (Benson, 2008; Dickinson, 1987). This concept exemplifies the shift from teacher-directed learning to an autonomous learning approach that aims to promote learner independence and processoriented learning (Sinclair, 2000). Holec $(1981$, p. 3) defined autonomy as "the ability to take charge of one's own learning," and clarified that this includes "determining the objectives, defining the contents and progressions, selecting methods and techniques to be used, monitoring the procedures of acquisition... and evaluating what has been acquired." Dam (2000) added that learners' self-evaluation of their own linguistic competence as well as their performance and social behavior can increase active involvement in the actual teaching and learning situation. Additionally, Wenden (1999) stated that it is essential to enable learners to gain self-monitoring strategies for them to identify the cause of their own difficulties and how to deal with them. An alternative, according to Oxford (1990), is to get students into the habit of self-reflection, a metacognitive strategy that enables them to manage their learning.

Despite its importance, assessing speaking activities is difficult for both teachers and students; judgment can be subjective without any concrete evidence. One way to address this problem

Language Education in Asia, 2012, 3(2), 146-158. http://dx.doi.org/10.5746/LEiA/12/V3/I2/A03/Yamkate_Intratat 
is to video record the performance, allowing it to be viewed as many times as necessary to accurately evaluate the speaker's strengths and weaknesses (Christianson, Hoskins, \& Watanabe, 2009).

Very few empirical studies address self-evaluation of learners' oral presentation skills, the focus of this study, particularly in English classes in Thailand. Sintupan (1990) audiotaped and transcribed eight secondary school students' oral presentations. The subjects corrected their transcriptions and recorded their work again. The teacher compared the two recordings. The results indicated that students corrected their own syntactic and morphological errors more effectively than lexical errors. Nevertheless, they needed teacher demonstration and guidance on how to identify the errors. To bridge this gap, Nuchanart (1992) prepared a five-point selfassessment scale focusing on content, organization, language accuracy, intonation, and pronunciation. Four undergraduate students audiotaped their presentations and evaluated their work using the scale. The students audiotaped and evaluated their work again, and then the researcher compared the forms. The process was done twice. The subjects were able to minimize their weaknesses, especially in content organization.

The subjects in both studies reflected that they had difficulty in evaluating their language proficiency and needed teacher support. Moreover, audiotapes, the main instrument, had some limitations, e.g., nonverbal codes, a crucial feature of oral presentations, could not be included in students' reflections. Oscarson (1989) noted earlier that video recordings are more beneficial than audio recordings for students in that they enable students to experience and evaluate the full spectrum of their communicative performance.

\section{Objectives}

A common problem in academic performance among Thai university students is their lack of both confidence and competency in oral communication and presentation skills. It is essential for teachers to help students overcome this obstacle.

This study originated from a teacher's attempt to help students in her speaking class to develop their oral presentation skills by drawing individual students' attention to the strengths and weaknesses of their videotaped performances. The study was conducted to find out (a) if and (b) in what ways video recordings facilitate students' evaluation of their oral presentation skills and their use of these evaluations to improve their performance.

In this study, the students were given recommendations on how to analyze verbal and nonverbal aspects of their performance while observing their videotaped presentations. Viewing these recordings was expected to facilitate students' self-development in presentation skills.

\section{Subjects}

\section{Methodology}

The subjects were nineteen undergraduate students in an Oral Communication course in the first semester of the 2011 academic year at a university in Thailand. All students were fourthyear engineering majors. Their language proficiency is at the intermediate level. The purpose and expected benefits of using video recordings were explained to the students when obtaining their consent to participate in the study. 


\section{Instruments}

The instruments were two sets of video recordings and two sets of questionnaires; each set was for one round of oral presentations. The students answered the first questionnaire (Appendix A) after watching his or her first video-recorded presentation. The students answered the second questionnaire, consisting of two sets of questions (Appendices A and B), after watching all of the second presentations. All student answers were in English.

\section{Process}

In class, students learned how to give good oral presentations and received the presentation evaluation criteria before they individually practiced a five-minute presentation. Each student's first presentation, an autobiography, was recorded. The class watched the video with the teacher and discussed the strong and weak points of the presenters in general, as an illustration of the questionnaire task. Each student received a copy of the video to watch at home as well as the first questionnaire to answer about his or her own performance. The questionnaire (Appendix A) consisted of open-ended questions about four presentation aspects:

1. verbal proficiency: accuracy in grammar, pronunciation, and fluency

2. body language: eye contact, posture, and gestures

3. quality of content: interestingness, relevance to the topic, appropriate expressions, and continuity

4. overall impression: strong points, weak points, and suggestions for further self-improvement

The second presentation was about students' favorite tourist place; the same process was applied. On the second questionnaire, to provide quantitative and qualitative information, students were asked the same questions as on the first questionnaire and also about the frequency of viewing the video, the comparison between their two presentations, the use of videos for self-assessment, and the best presentation.

\section{Data Analysis}

The students' comments about their verbal and nonverbal proficiency and quality of content were analyzed by the researchers on a 5-point scale, from the highest (5) to the lowest (1). Best's (1981) ranking was applied as follows:

$$
\begin{aligned}
& 4.20-5.00=\text { the highest } \\
& 3.40-4.10=\text { high } \\
& 2.60-3.30=\text { moderate } \\
& 1.80-2.50=\text { low } \\
& 1.00-1.70=\text { the lowest }
\end{aligned}
$$

The data was computed by t-test to compare the results between the first and second questionnaires. Statistical significance was set at $p<.05$. The students' suggestions for further improvement were analyzed by case-summary test and frequency.

\section{Results}

\section{Verbal Proficiency, Body Language, and Quality of Content}

Questionnaire 1. The data was computed for means (see Table 1). Regarding verbal proficiency, the students rated their performance moderate in grammar (3.10), pronunciation (3.00), and fluency (3.15). They also rated their body language as moderate for eye contact (3.15), posture (2.84), and gestures (2.94). The students considered that the content was very 
interesting (3.36). The relevance of their talk was rated the highest (4.21). The use of appropriate expressions was rated moderate (2.94), as was the continuity of the talk (3.36).

Students were clearly moderately satisfied with their first performance. They saw some mistakes in posture, gestures, and the use of appropriate expressions. However, they were highly satisfied with the relevance of their talk to the topic.

Questionnaire 2. The data was also computed for means. The students rated their verbal proficiency as high in grammar (4.05), pronunciation (3.94), and fluency (3.94). They also rated their body language as highly proficient in eye contact (4.00), posture (3.63), and gestures (3.89). Regarding quality of content, they considered interestingness (4.36), relevance (4.94), and continuity (4.21) to be at the highest level. The use of appropriate expressions was rated high (4.10).

Questionnaires 1 and 2. From the means of data, it was evident that the students were more satisfied with their second performance than with the first. They considered their verbal proficiency, nonverbal performance, and the quality of the content much improved. The different ratings between the two presentations were statistically significant at 0.05 levels, as shown in Table 1. 
Table 1

Questionnaires 1 and 2:

Comparison of Verbal and Nonverbal Proficiency, and Quality of Content

\begin{tabular}{|c|c|c|c|c|c|}
\hline \multicolumn{6}{|c|}{ Paired Samples Statistics } \\
\hline & Paired Comparison & Mean & $N$ & $\begin{array}{c}\text { Std. } \\
\text { Deviation }\end{array}$ & $\begin{array}{c}\text { Sig. } \\
\text { (2- tailed) }\end{array}$ \\
\hline \multirow[t]{2}{*}{ Pair 1} & Grammar 1 & 3.1053 & 19 & .45883 & \multirow{2}{*}{.000} \\
\hline & Grammar 2 & 4.0526 & 19 & .70504 & \\
\hline \multirow[t]{2}{*}{ Pair 2} & Pronunciation 1 & 3.0000 & 19 & .81650 & \multirow{2}{*}{.000} \\
\hline & Pronunciation 2 & 3.9474 & 19 & .84811 & \\
\hline \multirow[t]{2}{*}{ Pair 3} & Fluency 1 & 3.1579 & 19 & .89834 & \multirow{2}{*}{.000} \\
\hline & Fluency 2 & 3.9474 & 19 & .70504 & \\
\hline \multirow[t]{2}{*}{ Pair 4} & Eye contact 1 & 3.1579 & 19 & .89834 & \multirow{2}{*}{.000} \\
\hline & Eye contact 2 & 4.0000 & 19 & .88192 & \\
\hline \multirow[t]{2}{*}{ Pair 5} & Posture 1 & 2.8421 & 19 & .95819 & \multirow{2}{*}{.004} \\
\hline & Posture 2 & 3.6316 & 19 & .76089 & \\
\hline \multirow[t]{2}{*}{ Pair 6} & Gesture 1 & 2.9474 & 19 & .91127 & \multirow{2}{*}{.000} \\
\hline & Gesture 2 & 3.8947 & 19 & .87526 & \\
\hline \multirow[t]{2}{*}{ Pair 7} & Interestingness 1 & 3.3684 & 19 & .89508 & \multirow{2}{*}{.000} \\
\hline & Interestingness 2 & 4.3684 & 19 & 68399 & \\
\hline \multirow[t]{2}{*}{ Pair 8} & Relevance 1 & 4.2105 & 19 & .85498 & \multirow{2}{*}{.002} \\
\hline & Relevance 2 & 4.9474 & 19 & .22942 & \\
\hline \multirow[t]{2}{*}{ Pair 9} & Expressions 1 & 2.9474 & 19 & 1.02598 & \multirow{2}{*}{.001} \\
\hline & Expressions 2 & 4.1053 & 19 & .87526 & \\
\hline \multirow[t]{2}{*}{ Pair 10} & Continuity of talk 1 & 3.3684 & 19 & 1.01163 & \multirow{2}{*}{.009} \\
\hline & Continuity of talk 2 & 4.2105 & 19 & .85498 & \\
\hline
\end{tabular}

An examination of what the students focused on in their ratings for both presentations reveals the following:

Language accuracy. The students indicated that they had difficulty with tenses, conjunctions, singular / plural, prepositions, subject-verb agreement, missing words, nouns / pronouns, and word forms.

There were a few grammatical mistakes, e.g., tense and conjunctions. I should use past form for events in the past. The conjunction "but" should be changed to "therefore" because the two clauses are cause and effect. (S1)

In analyzing pronunciation, every student's judgment was based on ending sounds, stress, and intonation, as illustrated by the teacher. Not many students considered that they spoke fluently, whereas the rest revealed that they still had difficulty with fluency, even those who thought that they did better in the second presentation. 
Body language. In both presentations, every student noticed whether they had made direct eye contact with the audience and whether they had maintained good posture and made good gestures.

I did not have eye contact with the audience. Most of the time, I looked at the slides or the teacher. I also had negative gesture and posture. I noticed that I often touched my sleeves and sometimes I leaned against the table. (S2)

Content quality. All students responded that their presentations were relevant to the topic and that they had used expressions needed for the tasks.

The content is relevant to the topic [travel] because it is all about a tourist attraction, e.g., where it is, what to see, how to go there, and why it is very interesting. (S3)

I used needed expressions to describe an interesting place and I could do it well. (S4)

The points, either positive or negative, that the students brought up show they had some doubts about the interestingness of their presentations and the consistency of the main topic or continuity in the presentation.

I think my presentation today is not much interesting because the audiences are familiar with that place. (S5)

The content is interesting because not many people have visited that place and I added details which some audience may not know. (S6)

I lacked continuity because I did not have a link between each part of the presentation. The reason was because I was excited and I could not remember what to say. (S7)

I had good continuity in my presentation because I presented each piece of information in accordance with the sequence of time and place. (S8)

It can be concluded that the students were concerned about the audience when they judged whether the content was interesting or not. However, in considering the continuity of the content, they made judgments based upon the coherence and cohesion of their presentation.

\section{Students' Overall Impressions}

Questionnaire 1. The students listed several aspects of their performance as their strong points, weak points, and items they thought were required for further self-improvement (see Table 2). Quality of content $(42.1 \%)$, body language $(36.8 \%)$, and fluency $(21.1 \%)$ were the most frequently cited strong points. Regarding weak points, the majority of students listed body language $(68.4 \%)$. Two students (S5 and S15) reported that they were partly satisfied with their body language in some aspects, but after watching the video, were aware that they should improve themselves in other aspects, so they rated body language as both strong and weak points. The second and third most frequently listed weak points were fluency $(42.1 \%)$ and selfconfidence (31.6\%). 
The comments about strong and weak points in body language and self-confidence corresponded with the students' suggestions for further self-improvement. Practice / preparation was listed second, showing student awareness of self-improvement. The majority of students listed both body language and practice and preparation as requiring improvement at $57.9 \%$. Next were self-confidence and pronunciation, both at $31.6 \%$.

Questionnaire 2. A majority of the students repeated that content quality was their strong point $(57.9 \%)$. Interestingly, practice / preparation was second in frequency $(42.1 \%)$, showing that the students practiced more for the second presentation than for the first. Body language was third in frequency, with the same percentage $(36.8 \%)$ as for the first questionnaire. However, only three students rated body language as a strong point for both presentations.

In considering weak points, body language was chosen the most frequently (57.9\%). Although the percentage was lower than for the first questionnaire, many students were still not satisfied with their body language. Self-confidence was second (42.1\%), an increase from the first questionnaire. It was clear that by watching the video, students more clearly realized their mistakes, resulting in a decrease of self-confidence. Pronunciation was third (26.3\%).

Regarding suggestions for further self-improvement, it was evident that most students were aware that practice / preparation was necessary to improve their overall performance, as it was the most frequent choice (68.4\%). Self-confidence (47.4\%) and body language (36.8\%) were the second and third improvements suggested.

\section{Table 2}

Presentations 1 and 2:

Comparison of Strong and Weak Points, and Suggestions for Self-Improvement

\begin{tabular}{|c|c|c|c|}
\hline Presentation & \multicolumn{3}{|c|}{ Strong Points } \\
\hline 1 & $\begin{array}{c}\text { Quality of Content } \\
41.2 \%\end{array}$ & $\begin{array}{c}\text { Body Language } \\
36.8 \%\end{array}$ & $\begin{array}{c}\text { Fluency } \\
21.1 \%\end{array}$ \\
\hline 2 & $\begin{array}{c}\text { Quality of Content } \\
57.9 \%\end{array}$ & $\begin{array}{c}\text { Practice / Preparation } \\
42.1 \%\end{array}$ & $\begin{array}{c}\text { Body Language } \\
36.8 \%\end{array}$ \\
\hline \multirow{2}{*}{1} & Body Language & Weak Points \\
\hline \multirow{2}{*}{2} & $68.4 \%$ & $42.1 \%$ & Self-Confidence \\
& Body Language & Self-Confidence & $31.6 \%$ \\
\hline \multirow{2}{*}{1} & $57.9 \%$ & $42.1 \%$ & Pronunciation \\
& \multicolumn{3}{|c|}{ Suggestions for Self-Improvement } \\
\hline \multirow{2}{*}{2} & Body Language & Practice / Preparation & Self-Confidence \\
& $57.9 \%$ & $57.9 \%$ & $31.6 \%$ \\
\hline & Practice / Preparation & Self-Confidence & Body Language \\
& $68.4 \%$ & $47.4 \%$ & $36.8 \%$ \\
\hline
\end{tabular}


Questionnaire 2: Additional questions. Students were asked about the frequency of viewing the video, the comparison between their two presentations, the use of videos for self-assessment, and the best presentation. The last question was intended to encourage the students to identify their own criteria for evaluating oral presentations.

Viewing frequency. The majority of the students (57.90\%) watched each recording three times; about one-third (36.84\%) watched it twice. Only one student watched each video only once. Excerpts of responses show the areas the students concentrated on:

I watched each recording 3 times. The first round is to get the overview of the presentation. I focused on the body language in the second round while my focus in the third time was the language accuracy and the content. (S2)

For the third round, I paid attention to the language and the audience to see whether and how far my presentation caught their attention. (S6)

In the third round, I focused not only on the language and content, but also the reaction of the audience while they were listening to my presentation. (S9)

My attention was on the overview of my presentation and I concentrated on the details of my strength and weakness in the second round. (S10)

I concentrated on non-verbal language in the first round and on the language and content for the second time. (S1)

The last excerpt is from the student who watched the recordings only once.

Before watching each recording, I asked my friends for their comments on my strength and weakness. Consequently, when I watched the videos, I concentrated particularly on my weak points and considered how I could improve myself. (S5)

Presentation preference. The majority of students (89.48\%) preferred their second presentation. Only one student liked the first presentation better and another liked both presentations equally.

I liked both of them equally because I was more fluent in the first recording, but the language and content of the second presentation was much better, whereas my body language was not as good as my first presentation. (S9)

Students who liked their second presentation better responded that they thought they could perform better because they had seen their difficulties in the first recording, and were wellprepared, more confident, and able to solve those difficulties.

Advantages of video recording. Students responded that the recordings enabled them to see their weaknesses and strengths, to repeatedly view any specific part of the recordings to detect their weak points, and to learn about the strengths of good presenters, which motivated them to improve themselves. 
It should be noted that a few students mentioned some disadvantages of video-recording presentations: the camera distracted them from concentrating on the presentation, they worried that not looking at the camera would be interpreted as a lack of eye contact with the audience, and watching the recordings was time consuming, particularly when they had to concentrate on their classmates' weaknesses and strengths in the second video.

Best presenter criteria. Students gave their criteria when nominating the best presenter. The top three criteria were the presenter's body language which reflected his or her confidence, the interestingness of content, and the presenter's fluency. Other criteria included pronunciation, language accuracy, and how much the audience understood the content.

\section{Discussion and Implications}

The questionnaire data showed that the students became aware of their verbal and nonverbal proficiency and mistakes after watching the videos. Even though self-evaluation of this kind has been criticized for being subjective and for using data from participants' questionable recollections, for both presentations, the majority of students reported that their strongest point was content quality and the weakest was body language. Therefore, it can be surmised that the students' awareness of their presentation skills and nonverbal components would not have been possible without video recordings which they could repeatedly watch. Further, the statistical evidence of the students' positive attitude towards video recording and their increased satisfaction with their second presentations imply that the students benefited from the recordings. The results indicate that video recordings facilitate both the development of students' presentation skills and their use of the evaluations to improve their performance.

Regarding how video recordings facilitate presentation skill development, every student except one responded that self-assessment was aided by repeatedly watching his or her performance on video. The evidence is that the students were able to notice and identify their ineffective use of body language, lack of self-confidence, and unclear pronunciation in both presentations. Most students also believed that the main cause of their performance weaknesses was a lack of practice and preparation, which affected their self-confidence and use of body language.

There are four implications of this study concerning the use of video recordings to facilitate student development of oral presentation skills.

First, self-assessment is an essential part of language learning. It encourages students to identify the strengths and weaknesses in their own performance. Nonetheless, students who are new to a self-directed learning approach need guidance and support from the teacher to evaluate themselves with sound justification. An example of a basic training tool could be a checklist of particular areas of verbal and nonverbal communication that will improve students' presentations.

Second, the use of a video recording is beneficial for self-assessment of oral presentation skills, as it enables students to observe themselves from the viewpoint of the audience. Students still need some training so they can use video recordings to evaluate and improve the full range of their verbal and, in particular, nonverbal communication skills.

Third, the visibility of the video camera may distract the speaker's attention away from the audience. A ceiling-mounted video camera would be less intrusive than one on a tripod. When only a regular video camera is available, the teacher and / or the researcher should discuss the benefits of video recording for learner self-improvement with the students. Students 
should be encouraged to have a positive attitude towards being videotaped so that they may experience less anxiety and shift their concentration to the process of self-development.

Lastly, students should be encouraged to be active learners who look for opportunities to practice and learn to develop themselves through available resources.

In contexts where recording equipment is unavailable, students can develop a checklist of oral presentation criteria. Individual students or, alternatively, a pair of students can then use the checklist. Another option is to have individual learners keep a journal for reflection based on the areas in which they want to improve.

\section{Conclusion}

Through viewing their video-recorded presentations, the students in this study realized the importance of practice and preparation to improve their presentation skills. In fact, the data supports the idea that students saw the relationship between practice and preparation, selfconfidence, and body language and realized that these aspects are essential to performing well in oral presentations. From the results of the study, it is evident that using video recordings facilitated the development of oral presentation skills. Nevertheless, some teacher support should be given to students to enable them to make full use of the recordings to achieve an awareness of their own strengths and weaknesses, with the aim of becoming effective oral presenters.

\section{Author Note}

Kulawadee Yamkate, Department of Language Studies, School of Liberal Arts, King Mongkut's University of Technology Thonburi; Charatdao Intratat, Department of Language Studies, School of Liberal Arts, King Mongkut's University of Technology Thonburi.

Correspondence concerning this article should be addressed to Kulawadee Yamkate, Department of Language Studies, School of Liberal Arts, King Mongkut's University of Technology Thonburi, Bangkok, Thailand, and Charatdao Intratat, Department of Language Studies, School of Liberal Arts, King Mongkut's University of Technology Thonburi, Bangkok, Thailand. E-mail: kunlawadee.yam@kmutt.ac.th; charatdao.int@kmutt.ac.th 


\section{References}

Benson, P. (2008). Teachers' and learners' perspectives on autonomy. In T. Lamb \& H. Reinders (Eds.), Learner and teacher autonomy: Concepts, realities, and responses (pp. 15-32). Philadelphia, PA: John Benjamins.

Best, J. W. (1981). Research in education (4 ${ }^{\text {th }}$ ed.). Englewood Cliffs, NJ: Prentice Hall.

Christianson, M., Hoskins, C., \& Watanabe, A. (2009). Evaluating the effectiveness of a videorecording based self-assessment system for academic speaking. Language Research Bulletin, 24, 1-15. Retrieved from http://web.icu.ac.jp/Irb/docs/Christianson-HoskinsWatanabe.pdf

Dam, L. (2000). Evaluating autonomous learning. In B. Sinclair, I. McGrath, \& T. Lamp (Eds.), Learner autonomy, teacher autonomy: Future directions (pp. 48-59). Harlow, England: Pearson.

Dickinson, L. (1987). Self-instruction in language learning. Cambridge, England: Cambridge University Press.

Holec, H. (1981). Autonomy and foreign language learning. Oxford, England: Pergamon.

Nuchanart, D. (1992). The effects of self-assessment on the development of oral presentation skills. (Unpublished MA thesis). King Mongkut's University of Technology Thonburi, Bangkok, Thailand.

Oscarson, M. (1989). Self-assessment of language proficiency: Rationale and applications. Language Testing, 6(1), 1-13. http://dx.doi.org/10.1177/026553228900600103

Oxford, R. L. (1990). Language learning strategies: What every teacher should know. New York, NY: Newbury House.

Sinclair, B. (2000). Learner autonomy: The next phase? In B. Sinclair, I. McGrath, \& T. Lamb (Eds.), Learner autonomy, teacher autonomy: Future directions (pp. 4-14). Harlow, England: Pearson.

Sintupan, S. (1990). Developing self-correction in speaking activity at secondary school level: An experiment in learner's linguistic independence. (Unpublished MA Thesis). King Mongkut's University of Technology Thonburi, Bangkok, Thailand.

Wenden, A. L. (1999). An introduction to metacognitive knowledge and beliefs in language learning: Beyond the basics. System, 274), 435-441. http://dx.doi.org/10.1016/S0346251X(99)00043-3 


\section{Appendix A \\ Self-Assessment for Oral Presentation I}

Name:

Date:

Please evaluate your presentation in the box provided (the best $=5$, good $=4$, fair $=3$, rather $\mathrm{bad}=2$, the worst $=1$ ) and give examples in the blanks.

\section{Verbal Proficiency}

\begin{tabular}{|ll} 
a. grammar & example \\
b. pronunciation & example \\
c. fluency & example
\end{tabular}

2. Body Language

\begin{tabular}{|ll} 
a. eye contact & example \\
b. posture & example \\
c. gesture & example
\end{tabular}

3. Quality of Content

\begin{tabular}{|ll} 
a. interestingness & example \\
b. relevance & example \\
c. expressions & example \\
d. continuity & example
\end{tabular}

4. Overall Impression

a. Your strong points

b. Your weak points

c. Suggested for further improvement 


\section{Appendix B}

\section{Self-Assessment for Oral Presentation II}

The self-assessment for the second oral presentation has the same set of questions as in Appendix A, with the addition of these extra questions:

1. How many times did you watch each video recording?

2. Which recording was better from your point of view?

3. What were the advantages of video recording?

4. Who was the best presenter and on what criteria? 